\title{
Strength characteristics of artificial organic soils stabilized with copolymer stabilizer
}

\author{
Chia-Wen Law ${ }^{1}$, Felix Ngee-Leh Ling ${ }^{1, a}$ and Boon-Khiang $\mathrm{Ng}^{2}$ \\ ${ }^{1}$ Faculty of Civil \& Environmental Engineering, University Tun Hussein Onn Malaysia, 86400 Parit Raja, Batu Pahat, \\ Johor, Malaysia \\ ${ }^{2}$ Dairen Chemical (M) Sdn. Bhd., Malaysia
}

\begin{abstract}
Organic soil is known as low strength material, and chemical stabilization is widely used to increase its bearing capacity. However, the use of traditional stabilizer has some limitations. Therefore, stabilization was carried out by using non-traditional stabilizer - Vinyl acetate-ethylene (VAE) copolymer emulsion in this study with the aim to determine its suitability to stabilize soil mixed with organic matter. Two types of artificial organic soil with kaolin: organic acid ratio of 5:5 (K5HA5) and 7:3 (K7HA3) were utilized. Control specimens were tested using pure kaolin. Different percentages of VAE $(5 \%, 7.5 \%, 10 \%)$ were added in order to determine the minimum amount of stabilizer required to achieve a minimum strength increment of a $345 \mathrm{kPa}$. The strength of samples was determined with automated unconfined compressive test device. Specimens were air cured for 7 days prior to testing. Both K7HA3 with $7.5 \%$ VAE and K5HA5 with 10\% VAE had achieved the minimum strength increment to be considered as effective stabilization. The strength of the artificial organic soil was found to be increasing with the increment of percentages of VAE used. Hence, it can be concluded that stabilizing mechanism of the artificial organic soils with VAE is not affected by organic matter.
\end{abstract}

\section{Introduction}

Modification of the engineering characteristics of organic soil is required to meet the design requirements before the development of the affected site is carried out. One of the usual practices of soil improvement method is soil stabilization. Soil stabilization improves the strength of soil through binding the soil particles together, proofing the particles or combination of both. There are several methods of soil stabilization, and these methods can be categorized into two broad categories, which are mechanical stabilization and chemical stabilization.

Mechanical stabilization achieved through mechanical process by induced vibration or compaction to alter the nature of native soil particles [1]. On the other hand, chemical stabilization depends mainly on the chemical reaction between stabilizer (cementitious material) and soil particles (pozzolanic material) to achieve desired strength [1]. Currently, the most traditional stabilizer that commonly used is lime. Lime stabilized soil effectively increases the strength, durability, workability, and compressibility of the soil [2]. However, the organic material decomposition blocked the polymerization of silicate and inhibited the pozzolanic reaction required in lime stabilized soil process

${ }^{\mathrm{a}}$ Corresponding author : felix@uthm.edu.my

(C) The Authors, published by EDP Sciences. This is an open access article distributed under the terms of the Creative Commons Attribution License 4.0 (http://creativecommons.org/licenses/by/4.0/). 
to gain strength [3]. Based on the findings of the research on cement stabilizer, which is another example of traditional stabilizer, it also not works well when there is an existence of organic matter and more admixtures needed for better soil strength [4]. Besides that, the organic content can affect the effectiveness of soil stabilization [5]. Due to the limitations of traditional stabilizers, technologies have increased the number of stabilizers. The polymer-based stabilizer is one of the non-traditional stabilizers which show a significant increase of unconfined compressive strength of the treated soil [6].

Currently, five types of polymers commonly used in concrete to improve flexural strength and tensile strength are acrylics, styrene-acrylics, vinyl acetate ethylene (VAE), polyvinyl acetate (PVA), and styrene-butadiene resin (SBR) [7]. Each of them has their unique characteristics such as adhesion, waterproof ability, and UV stability. Both vinyl acetate and acrylic copolymers are hydrophobic and showed moderate bonding efficiency in a range of soils in different case studies [8]. Besides that, previous study [9] also found that the vinyl acetate-acrylic copolymer can effectively increase the unconfined compressive strength of the peat soil. The peat soil is classified as the soil with high content of organic matter. The findings proved that the copolymer stabilizers have a positive impact in organic soil stabilization.

The polymer stabilizer coats soil particles and the physical bonds are formed when the emulsion water evaporates, leaving a soil polymer matrix. The improvement in strength is depends on the ability of the stabilizers to coat the soil particles adequately and physical properties of stabilizers due to the primary stabilization mechanism is physical bonding. Therefore, the polymer stabilizers are more suitable for the granular soils as compared to the fine grained soils due to the higher mixing efficiency resulting from their high specific surface area. Other than that, it is typically used in soil with excellent tensile and flexural strength and producing physical bonds with excellent strength [10]. Even though polymer stabilization demonstrates a great increases in unconfined compression strength in dry curing but is found to decrease after it is immersed in water [11]. This is due to the weakness of the hydrogen bonding to neutralize electrically clay mineral and also the ineffectiveness of the polymer to decrease the permeability of the mixture. Polar components present in polymer absorb strongly on the soil surfaces which promoting adhesion and resulting in the increases of strength [10]. In spite of growing interest on copolymer soil stabilization, there is limited number of researches has been published. Most of the investigation focused on the effectiveness of the soil stabilization rather than the mechanism of the process occurred during the soil stabilization.

Moreover, there are limited studies on the other types of the copolymer, namely VAE copolymer emulsion which also have the potential to increase the strength of stabilized soil. Hence, this study is carried out with the objective to stabilize organic soils with VAE stabilizer.

\section{Material and methods}

\subsection{Material properties}

The artificial organic soil was prepared by mixing inorganic soil with predetermined humified organic matter. In this study, two different ratios of inorganic soil vs. organic matter which was 5:5 and 7:3 were used to compare their effects on soil stabilization. The type of organic matter utilized in this study is organic acid which is categorized as humified organic matter while the inorganic soil used in this study is Kaolin grade S300. Some of the physical and chemical properties of Kaolin grade S300 and organic acid were determined by other researchers and are shown in Table 1 [12, 13], Table 2 [14] and Table 3 [15], respectively. Based on the USCS classification, kaolin S300 is categorized as low plasticity Silt (SL) which consists of $95 \%$ alumina and silicate. Whereas the organic acid utilized in this study was found to be consisted of humic acid and fulvic acid which is fall in the category of humified organic matter. 
Table 1. Physical and chemical properties of kaolin grade $S 300[12,13]$.

\begin{tabular}{|c|c|}
\hline \multicolumn{2}{|c|}{ Kaolin grade S300 } \\
\hline Properties & Value \\
\hline \% Sand & $0.14 \%$ \\
\% Silt & $94.94 \%$ \\
$\%$ Clay & $4.92 \%$ \\
$\mathrm{D}_{60}$ & $22.83 \mu \mathrm{m}$ \\
$\mathrm{D}_{30}$ & $12.22 \mu \mathrm{m}$ \\
$\mathrm{D}_{10}$ & $4.44 \mu \mathrm{m}$ \\
$\mathrm{C}_{\mathrm{u}}$ & 5.142 \\
$\mathrm{C}_{\mathrm{c}}$ & 1.473 \\
$\mathrm{LL}$ & $33.75 \%$ \\
$\mathrm{PL}$ & $23.01 \%$ \\
$\mathrm{PI}$ & $10.74 \%$ \\
$\mathrm{pH}\left(\right.$ at $\left.25^{\circ} \mathrm{c}\right)$ & 6.82 \\
\hline
\end{tabular}

Table 2. The bulk chemical composition of the kaolin grade S300 [14].

\begin{tabular}{|c|c|}
\hline \multicolumn{2}{|c|}{ Kaolin grade S300 } \\
\hline $\begin{array}{c}\text { Bulk chemical } \\
\text { composition }\end{array}$ & $\begin{array}{c}\text { Composition } \\
\text { (\%) }\end{array}$ \\
\hline $\mathrm{SiO}_{2}$ & 54.2 \\
$\mathrm{Al}_{2} \mathrm{O}_{3}$ & 40.8 \\
$\mathrm{SO}_{3}$ & - \\
$\mathrm{CaO}$ & - \\
$\mathrm{Fe} 2 \mathrm{O} 3$ & 1.51 \\
$\mathrm{TiO} 2$ & 0.59 \\
$\mathrm{MgO}$ & 0.36 \\
$\mathrm{~K} 2 \mathrm{O}$ & 2.21 \\
$\mathrm{Na} 2 \mathrm{O}$ & - \\
$\mathrm{Cl}$ & - \\
$\mathrm{BaO}$ & - \\
$\mathrm{SrO}$ & - \\
\hline
\end{tabular}

Table 3. Composition of organic acid [15].

\begin{tabular}{|c|c|}
\hline Humic acid & Fulvic Acid \\
\hline $61.68 \%$ & $24.93 \%$ \\
\hline
\end{tabular}

Table 4. The physical properties of DA-524 [16].

\begin{tabular}{|c|c|}
\hline Emulsifying system & PVA \\
\hline Solid content (\%) & $55 \mathrm{~min}$ \\
\hline Viscosity (cP) & $1500-2500$ \\
\hline pH & $4.5-6.5$ \\
\hline Free monomer (\%) & $0.3 \mathrm{max}$ \\
\hline Wet Tack & Good \\
\hline Thickening response & Good \\
\hline Borax stability & No \\
\hline Tg $\left({ }^{\circ} \mathbf{c}\right)$ & 20 \\
\hline MFFT $\left({ }^{\circ} \mathbf{c}\right)$ & 3 \\
\hline
\end{tabular}

Copolymer stabilizer VAE DA-524 was chosen to stabilize the artificial organic soil in this study. The VAE DA-524 emulsion was supplied by DAIREN Chemical Sdn. Bhd. VAE emulsion can be characterized as copolymer as it derived from two species monomers which are Vinyl Acetate monomer and Ethylene monomer. Vinyl acetate ethylene (VAE) emulsions are referred to emulsion 
derived from the copolymerization of vinyl acetate and ethylene. The total formulation of vinyl acetate is in the range between 60 and 95 percent, and the ethylene content ranges between 5 and 40 percent. VAEs appear as milky white water-based emulsions, and high-pressure reactors are required to synthesize VAE emulsions from vinyl acetate monomer and ethylene. The physical properties of DA-524 [16] are listed in Table 4.

\subsection{Methods}

The artificial organic soils utilized in this study were categorized as fine materials with majority particles smaller than $63 \mu \mathrm{m}$ [12]. Therefore, small pycnometer test [17] was used to determine the specific gravity of all the soil samples. Kerosene was used as displacement liquid because distilled water is solvent for organic acid. Standard Proctor compaction test [18] was performed on all types of soil in order to identify its optimum moisture content to achieve the maximum dry density.

Cylindrical shaped test specimens of dimension $50 \mathrm{~mm}$ in diameter and $100 \mathrm{~mm}$ in height were prepared based on the predetermined maximum dry density. The contents of water utilized to remold specimens were based on its optimum moisture content as obtained from Standard Proctor compaction test. Extra water of $0.02 \%$ was added after considering the water losses due to hydration of VAE copolymer emulsion with soil during mixing. The losses of water through hydration were determined using Eqn. 1. A total of 36 samples were remolded in this study and its details are shown in Table 5. The specimens were air cured for seven days at room temperature. The water content of specimens was determined before and after curing. After air curing, the specimens were tested for its unconfined compression strength using automated Unconfined Compression Test device. A constant axial force was imposed on the test specimen with the constant strain rate of $1 \% / \mathrm{min}$ until failure occurs (does not exceed $2 \% / \mathrm{min}$ as specified in standard specification [19]). Failure was considered taken place when the axial stress showed decreasing with increasing strain or a strain of $20 \%$ was exceeded (whichever comes first) in accordance to standard specification[19]. The data of the test was utilized to calculate the unconfined compressive strength of the soil.

Table 5. Details of soil specimen.

\begin{tabular}{|c|c|c|c|c|}
\hline \multirow{3}{*}{ Types of Soil } & \multirow{3}{*}{$\begin{array}{l}\text { Kaolin: Organic Acid } \\
\text { ratio (Coding name of } \\
\text { soil) }\end{array}$} & \multirow{2}{*}{\multicolumn{3}{|c|}{$\frac{\text { Percentage of VAE emulsion copolymer, } \%}{\text { Number of replicates, } n}$}} \\
\hline & & & & \\
\hline & & $5 \%$ & $7.5 \%$ & $10 \%$ \\
\hline \multirow{2}{*}{$\begin{array}{l}\text { Artificial Organic } \\
\text { Soil } \\
\end{array}$} & 5:5 (K5HA5) & 3 & 3 & 3 \\
\hline & $7: 3$ (K7HA3) & 3 & 3 & 3 \\
\hline Inorganic Soil & $\begin{array}{c}10: 0 \\
\text { (Pure kaolin) }\end{array}$ & 3 & 3 & 3 \\
\hline \multicolumn{2}{|c|}{ Total specimens } & 9 & 9 & 9 \\
\hline
\end{tabular}

water loses due to hydration

$$
=\left[\frac{\text { water content before mixing }- \text { water content after mixing }}{\text { water content before mixing }}\right]
$$

\section{Results and discussion}

\subsection{Physical properties of soil specimens}

The optimum moisture content and maximum dry density of tested soil was determined using Standard Proctor Compaction test [18]. The compaction curves of the test specimens are shown in Figure 1 and its maximum dry density and optimum moisture content are listed in Table 6 . The test results showed that the optimum moisture content was increased with contents of organic acid, whereas maximum dry density of tested soils was decreased with contents of organic acid. Besides 
that, the results of specific gravity (as listed in Table 6) also showed that the organic acid has significantly influenced the physical properties of soil. The specific gravity of soil was found to be decrease with increased contents of organic acid.

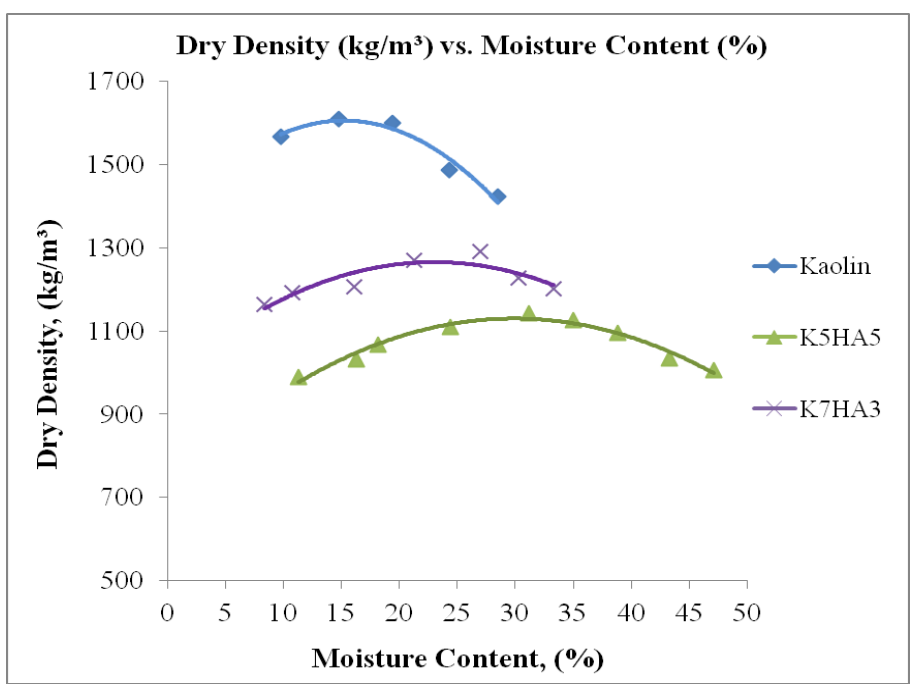

Figure 1. Compaction curves of kaolin S300 and artificial organic soils

Table 6. Specific gravity, maximum dry density and optimum moisture content of kaolin S300 and artificial organic soils.

\begin{tabular}{|c|c|c|c|c|}
\hline \multirow{2}{*}{ Types of Soil } & Kaolin: Organic Acid ratio & \multicolumn{3}{|c|}{ Properties } \\
\cline { 3 - 5 } & (Coding name of soil) & $\begin{array}{c}\text { Specific } \\
\text { gravity }\end{array}$ & $\begin{array}{c}\text { Maximum } \\
\text { dry density } \\
\text { (kg/m3) }\end{array}$ & $\begin{array}{c}\text { Optimum } \\
\text { moisture } \\
\text { content (\%) }\end{array}$ \\
\hline \multirow{2}{*}{ Artificial Organic Soil } & $5: 5$ (K5HA5) & 2.03 & 1130 & 31 \\
\cline { 2 - 5 } & $7: 3$ (K7HA3) & 2.24 & 1260 & 23 \\
\hline Inorganic Soil & $10: 0$ (Pure kaolin) & 2.59 & 1605 & 15 \\
\hline
\end{tabular}

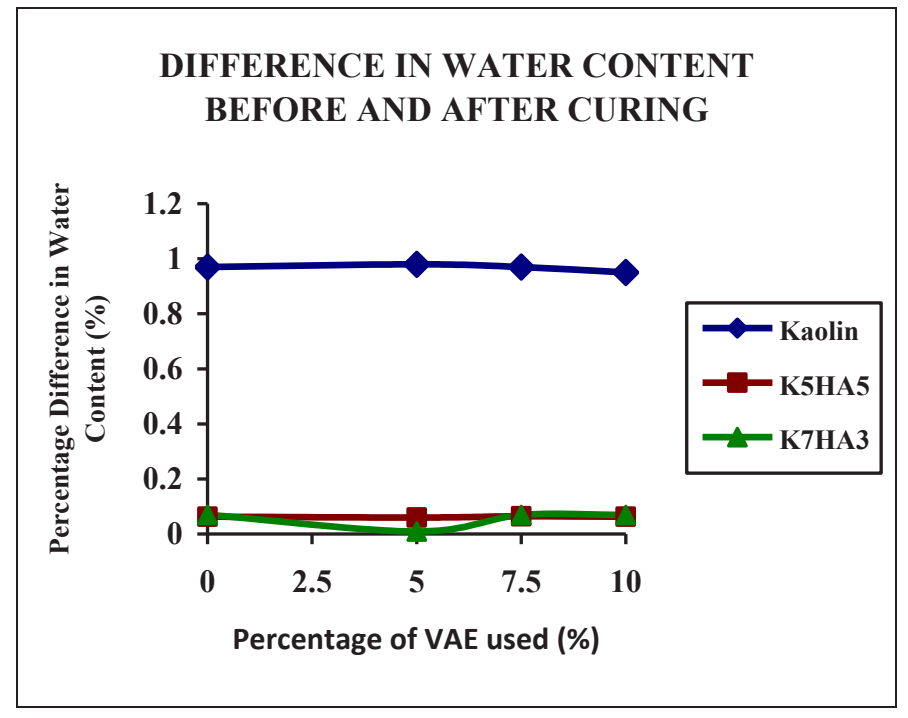

Figure 2. Loses of water throughout curing periods 
The water content of specimens were determined before and after curing in order to determine other potential factors that may influence the strength of specimens. The losses of water throughout curing periods were determined and illustrated in Figure 2. The findings showed that the losses of water were relatively higher (almost $1 \%$ ) for plain kaolin soil comparing with artificial organic soils which were around $0.1 \%$. The findings showed that the contents of organic acid had increased the water holding capacity of soil. Organic acid is found to be capable in attracting water through adsorption process [20].

\subsection{Effect of organic acid on unconfined compressive strength of soils}

It is shown in Figure 3 that the UCS of both types of artificial organic soil K7HA3 (with 70\% kaolin mixed with $30 \%$ organic acid) and K5HA5 (with $50 \%$ kaolin mixed with $50 \%$ organic acid) were higher than kaolin grade S300 with the use of the same amount of VAE copolymer emulsion. In comparison to the specimens of pure kaolin S300, the strength increment is due to the composition of the organic acid in the soil. In fact, the negatively charged organic acid itself is not a flocculating agent, and they are even an effective dispersing agents for Na-clays and soils [21]. However, with the presence of polyvalent cation, it can effectively facilitate the attachment of the polyanions from humic acid to clay surfaces and to bridge clay particles together, forming stable aggregates and increasing the strength of the soil [21]. It is thus proven that, with the presence of polyvalent cations in kaolin, humic substances in soil are likely to play a vital role in soil aggregate stabilization. In this study, the polycations which are $\mathrm{Al}$ from the kaolin possibly had facilitated the polyanions from the humic acid to increase the ability of soil aggregation which resulted in higher UCS of the soil specimens.

Besides that, as the humic substances become intimately associated with the mineral fraction of soil, colloidal complexes of humus-clay and humus silt aggregates are formed. These aggregated humus aggregates are formed by electrical processes which increase the cohesive forces that cause very fine soil particles and clay components to attract to each other and thus increasing its strength [22]. Hence, the unconfined compressive strength of K7HA3 and K5HA5 are higher than the pure kaolin grade $\mathrm{S} 300$ which is without the composition of organic content.

On the other hand, it is found that the UCS of K7HA3 is greater than K5HA5. This statement can be supported by the result of the previous research which showed that at low organic contents the soil particles tend to aggregate, whereas at higher organic contents the soil particles tend to disperse [23]. Also, the organic particles are stiff when compressed and act as rigid particles when dry, but when they absorb water, they become soft and sponge-like. Therefore, at higher water contents, specimens with higher levels of organic matter had lower soil strength because on the wetter side of the peak strength values, soil lumps had been slaked, and the excess water caused greater pore water pressure. Therefore, compaction effort was merely sheared or remolded the specimens rather than increased soil strength further [22]. The findings can explain the result of the K5HA5 with higher organic content obtained a lower strength than K7HA3 in this study.

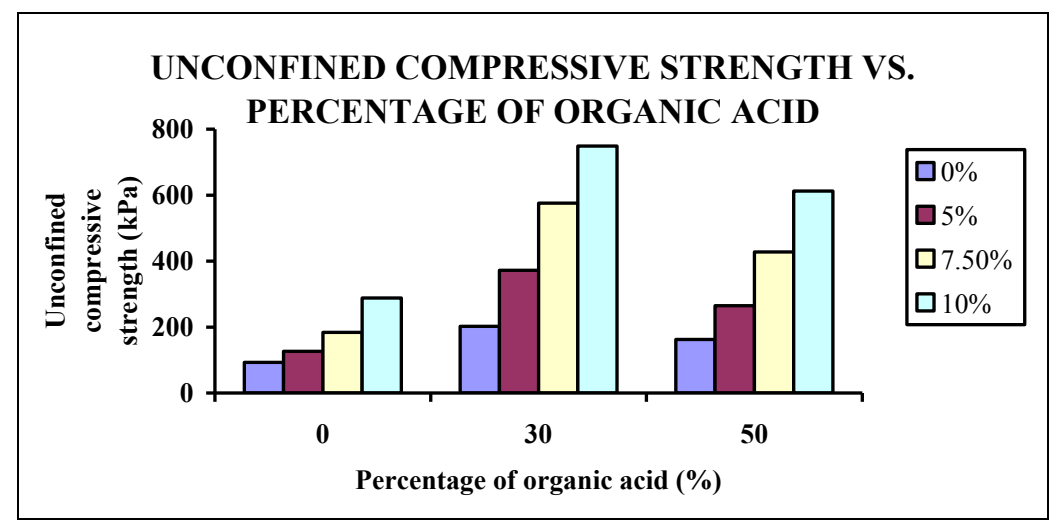

Figure 3. Effect of organic acid on unconfined compressive strength of soil 
It is also proven that the physical properties of soil are not directly contributed to the unconfined compressive strength. As shown in Figure 3, the kaolin had achieved the highest dry density as compared to K7HA3 and K5HA5. However, the unconfined compressive strength of the K7HA3 is the highest and followed by K5HA5 and pure kaolin grade S300. The findings agreed well with the previous study $[23,24]$ in which the moisture content and density of specimens were found not to be statistically significant with the strength of stabilized soil.

\subsection{Effects of VAE copolymer emulsion on unconfined compressive strength of soil}

Figure 4 shows the experimental results on the effect of percentages of VAE copolymer emulsion on the unconfined compressive strength (UCS) of soils. It is evident from the findings that the contents of VAE copolymer emulsion influenced the UCS of the test specimens. The UCS of all three types of soil achieved the highest values when the percentages of the VAE copolymer emulsion were $10 \%$. As stated in standard specification [25], an increase in UCS of $345 \mathrm{kPa}$ or more must be achieved for stabilization to be considered effective. Therefore, it is clearly found that for kaolin grade S300 with even up to $10 \% \mathrm{VAE}$, the strength of soil still below the target strength of $345 \mathrm{kPa}$. Besides that, the minimum target of UCS for the K5HA5 and K7HA3 to achieve were $507.35 \mathrm{kPa}$ and $547.05 \mathrm{kPa}$ respectively. As shown in the graph, the usage of $10 \%$ of VAE copolymer emulsion in K5HA5 had met the minimum target of strength increment whereas the $7.5 \%$ usage of VAE copolymer emulsion in K7HA3 were also considered as the effective stabilizer.

The main reason that contributed to this result can be explained by the mechanism of reaction between polymer composed of polyvinyl acetate and soil. The clayey soil stabilization mechanism of organic polymer soil stabilizer includes filling, chemical reaction and enwrapping. A polymer comprised of polyvinyl acetate contains long-chain macromolecule and polarity carboxyl (-OOCCH3). When it is applied to clayey soil, a part of polymer fill up the voids of soil, and other parts stay on the soil aggregates surface. The hydrophilic groups $\left(-\mathrm{OOCCH}_{3}\right)$ in its molecular structure have a chemical reaction with positive ions of clay grain and create physicochemical bonds between molecules and soil aggregates with ionic, hydrogen, or Van der Waals bonds. Through these bonds, long-chain macromolecules of polymers enwrap the aggregate's surface and interlink to form an elastic and viscous membrane structure [9]. Therefore, the strength of the soil is improved. Besides that, the formation of the voids filling and physico-chemical bond in reactions of stabilized soil leads to the increases in bonding and interlocking forces between soil particles [10]. As a result, the unconfined compressive strength and cohesion of the clayey soil are improved.

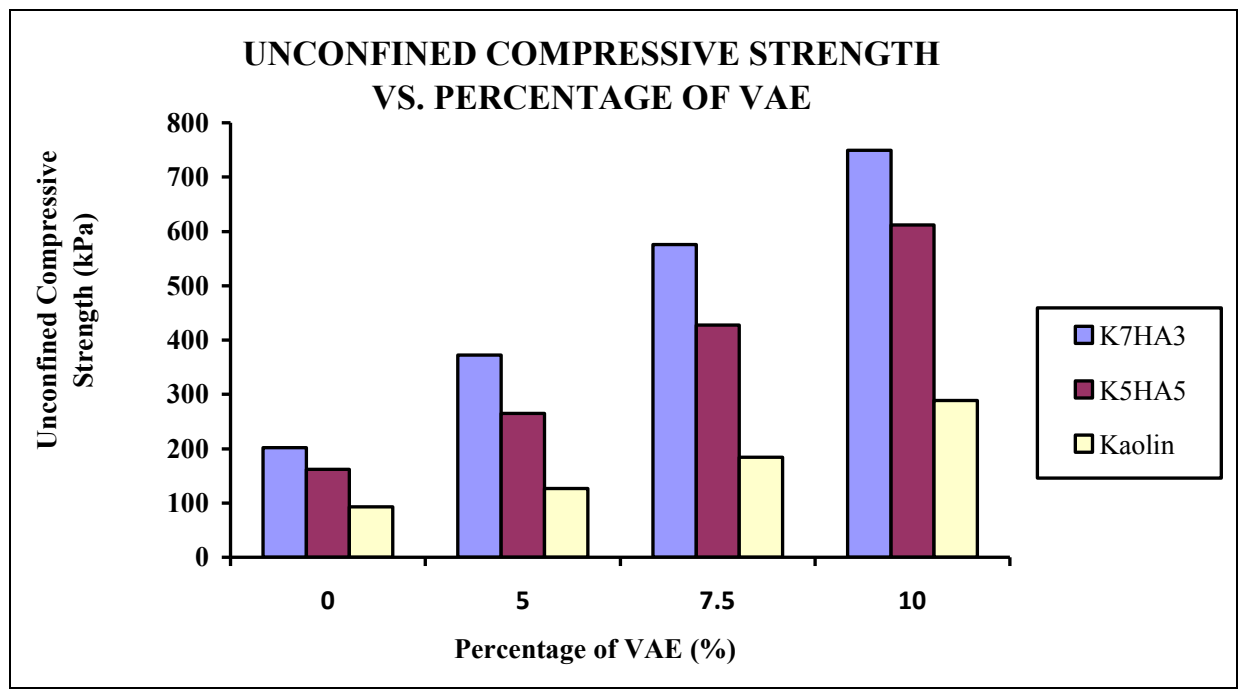

Figure 4. Effects of VAE copolymer emulsion on the unconfined compressive strength of the soil 
Given the concentration of polymer on strength, more addition amount can fill up more voids and produce more bonds and hence result in the greater strength of the soil. However, the addition amount of polymer is related to the void ratio and clay content. At a certain concentration, the molecules of polymer might have already been enough to fill up most of the soil voids and the hydrophilic groups (-OOCCH3) in molecule might have fully reacted with the clay particle. Therefore, that predetermined concentration can be referred as optimum concentration. In this study, the optimum percentages of VAE copolymer that can use to achieve the maximum value of UCS are still undefined as the pattern of the graph is still increasing. Therefore, there must be an optimum usage of VAE copolymer emulsion to achieve the maximum UCS.

\section{Conclusions}

Artificial organic soil stabilized with VAE copolymer emulsion had been studied. It can be summarized from the experimental outcomes that VAE copolymer has made a substantial effect on the strength properties of the stabilized organic soil. Based on the results of laboratory investigation, the following concluding remarks were made:

1. The UCS of the artificial organic soil is increasing with the increment of copolymer stabilizer used.

2. According to ASTM D-4609, the stabilization considered as useful if there is an increment of $345 \mathrm{kPa}$ in unconfined compressive strength. In this study, stabilized kaolin grade $\mathrm{S} 300$ have not achieved the target with up to $10 \%$ VAE. In contrast, the K5HA5 with $10 \% \mathrm{VAE}$ copolymer emulsion and K7HA3 with $7.5 \%$ had successfully achieved target strength increment.

3. The K7HA3 had reached the highest unconfined compressive strength for all the percentages of VAE copolymer emulsion used, and it is then followed by K5HA5 and kaolin grade S300. Therefore, it can be concluded that VAE copolymer emulsion is able to stabilize soils with organic matter (higher strength gained in artificial organic soils compared to pure kaolin). However, high amount of organic matters when comparing soil K5HA5 with K7HA3, the strength is slightly affected.

\section{Acknowledgements}

The authors wish to express gratitude and grateful appreciation to the financial support from University Tun Hussein Onn Malaysia and Dairen Chemical (M) Sdn. Bhd. The authors also thank all laboratory technicians in Research Centre for Soft Soil (RECESS), Department of Infrastructure and Geomatic Engineering, Department of Water and Environmental Engineering of Faculty of Civil and Environmental Engineering, Universiti Tun Hussein Onn Malaysia. Their advice, knowledge and technical support had made this research possible.

\section{References}

1. G.P. Makusa, Soil stabilization methods and materials in engineering practice: State of the art review (Lulea ${ }^{\circ}$, Sweden, 2013)

2. T.I. Jawad, M.R. Taha, Z.H. Majeed and T.A. Khan, Res. J. Appl. Sci. Eng. Technol., 8(4), 510520 (2014)

3. M.B. Hampton and T. B. Edil, GSP No. 81 (New York, USA, 1998)

4. H. Chen and Q. Wang, Bull. Eng. Geol. Environ., 65(4), 445-448 (2006)

5. E.O. Tastan, T.B. Edil, C.H. Benson, and A.H. Aydilek, J. Geo. Geoenv. Eng., 137(9), 819-833 (2011)

6. A.R. Zandieh and S.S. Yasrobi, Geo. Geol. Eng., 28(2), 139-145 (2010)

7. J. Nasvik, in Concrete construction (Addison, USA, Sept 2001) 
8. GRT, Polymer Soil Stabilization (2015), available at https://globalroadtechnology.com/polymersoil-stabilization.

9. P.F.I. Norazam, MATEC Web Conf., 103, 07014 (2017)

10. J. Tingle, J. Newman, S. Larson, C. Weiss and J. Rushing, Transp. Res. Rec., 1, 59-67 (1989)

11. A. Bayat and O. Farzaneh, in Advances in transportation geotechnics 2, edited by S. Miura, T. Ishikawa, N. Yoshida, Y. Hisari, and N. Abe (CRC, Boca Raton, FL, 2012), p.59

12. F.N.L. Ling, K.A. Kassim and A.T. Abdul Karim, Adv. Mater. Res., 341-342, 108-112 (2012)

13. F.N.L. Ling, K.A. Kassim and A.T. Abdul Karim, in Proceedings of peat technologyopportunities and challenges seminar (UCTS, Sibu, 2014)

14. F.N.L. Ling, K.A. Kassim, A.T. Abdul Karim and T.W. Chan, Adv. Mater. Res, 723, 985-992 (2013)

15. M.I. Jaimi, Report No. BK 35/14, Forest Research Institute Malaysia (FRIM) (2014)

16. Dairen Chemical Corporation (DCC), Technical Data Sheet VAE DA-524 (2016)

17. BSI, BS 1377: Part 2 (1990)

18. BSI, BS 1377: Part 4 (1990)

19. BSI, BS 1377: Part 7 (1990)

20. K.H. Tan, Principles of Soil Chemistry (Third edition) (CRC, Boca Raton, FL, 1998)

21. A.I. Husein Malkawi, A.S. Alawneh and O.T. Abu-Safaqah, Appl. Clay Sci., 14(5-6), 257-278 (1999)

22. R.E. Pettit, Organic matter, humus, humate, humic acid, fulvic acid and humin: their importance in soil fertility and plant health (2004), available at http:// www.humates.com/pdf/ORGANICMATTERPettit.pdf

23. F.N.L. Ling, K.A. Kassim, A.T. Abdul Karim and S.C. Ho, Adv. Mater. Res., 905, 305-308 (2014)

24. A. Bauer, Farm Res., 31, 44-52 (1974)

25. ASTM Int., D4609-01, in ASTM Standard 04.08 (2001) p.1-5 